
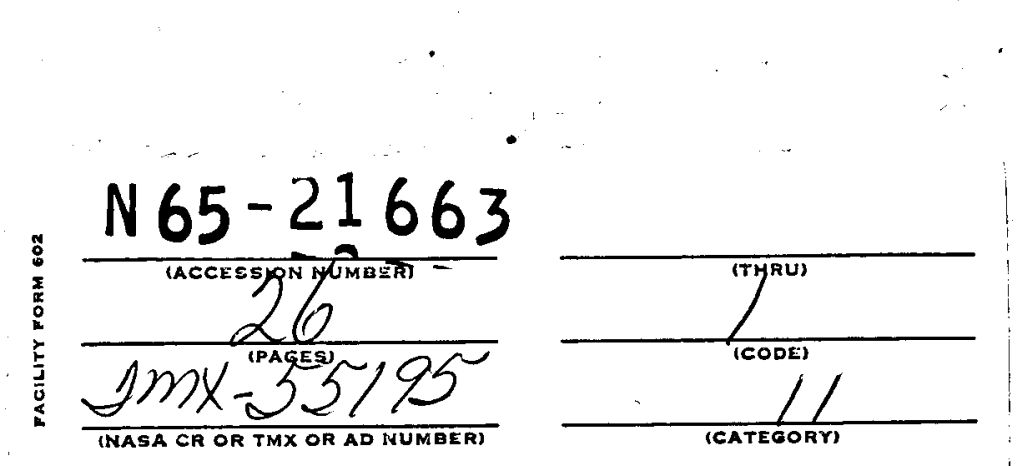

\title{
CRYOSORPTION - A METHOD FOR SIMULATING \\ THE SPACE VACUUM \\ ENVIRONMENT
}
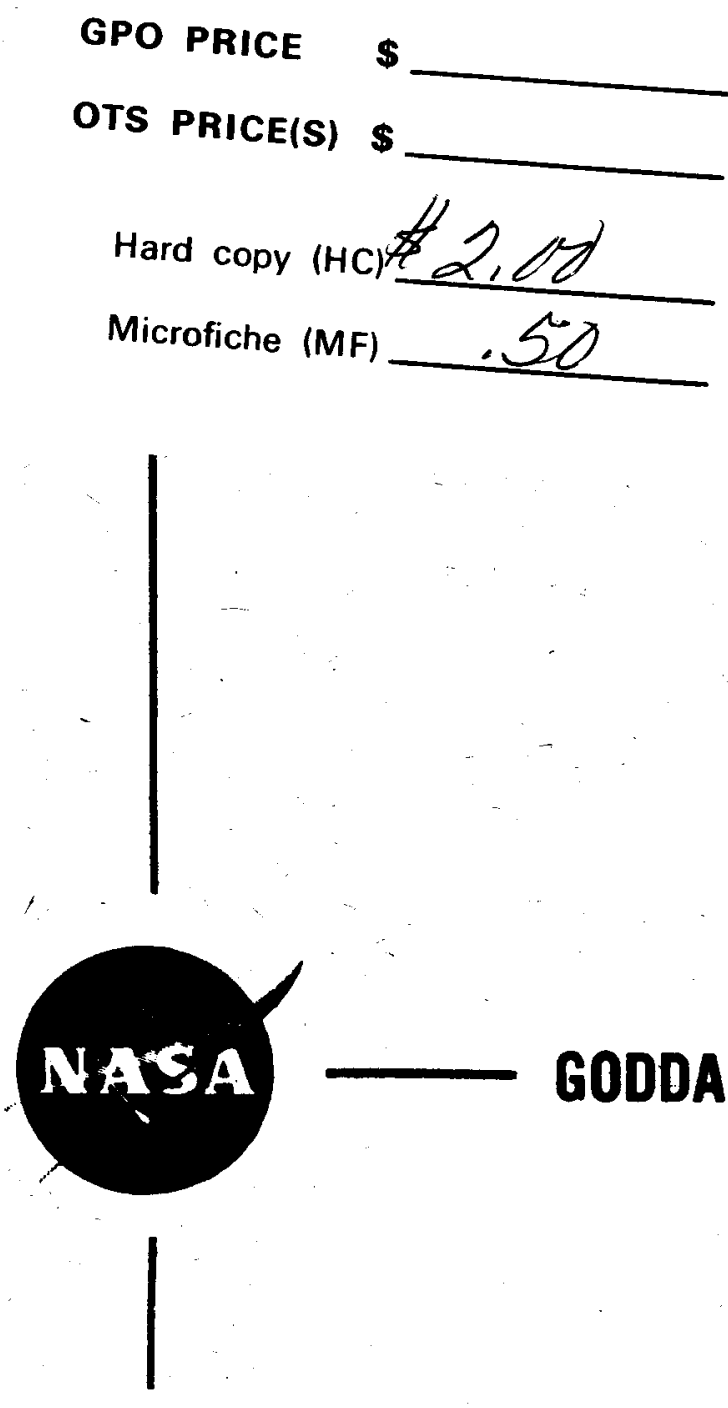

JANUARY 26, 1965 
Copy No. 16

\author{
CRYOSORPTION - A METHOD \\ FOR SIMULATING \\ THE SPACE VACUUM \\ ENVIRONMENT
}

January 26, 1965

THERMODYNAMICS BRANCH

TEST AND EVALUATION DIVISION

OFFICE OF TECHNICAL SERVICES, GSFC 


\author{
CRYOSORPTION - A METHOD \\ FOR SIMULATING \\ THE SPACE VACUUM \\ ENVIRONMENT
}

Prepared by:

Reviewed by:

Approved by:
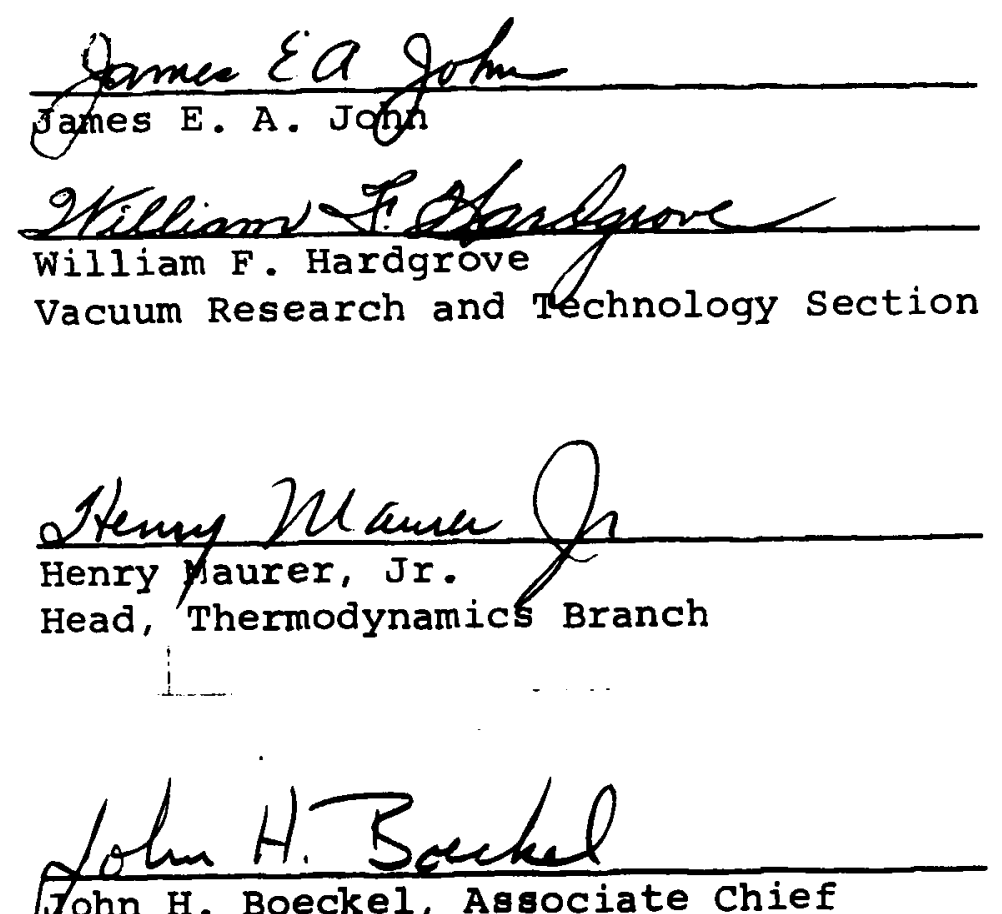

John H. Boeckel, Associate Chief

Test and Evaluation Division

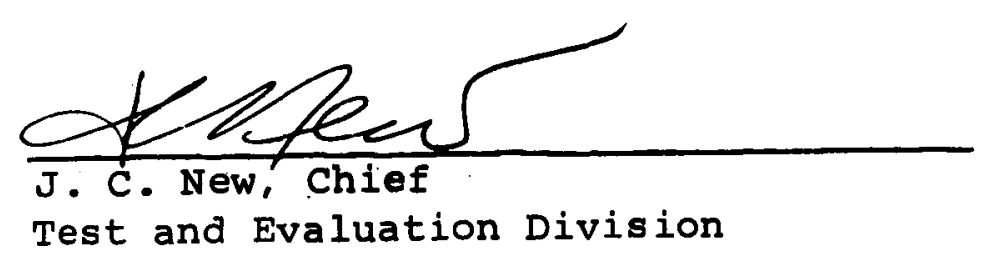




\section{STATUS}

The system described is at present under contract to the Linde Division, Union Carbide Corporation, and is scheduled for delivery in August 1965.

\section{AUTHORIZATION}

GSFC Job order No. 322-Y-09-04 


\section{CRYOSORPTION - A METHOD \\ FOR SIMIJLATING}

THE SPACE VACUUM

ENVIRONMENT

by

J. E. A. John - W. F. Hardgrove

Goddard Space Flight Center

\section{SUMMARY}

The first generation of space simulators are capable of operating down to $10^{-8}$ torr. This level of vacuum limits the testing and evaluation of spacecraft to problems dealing with corona and thermal balance. These test chambers are adequate for establishing the functional dependability of spacecraft with short duration, low level missions.

Future missions requiring more sophisticated and complex systems for spacecraft with long term duration in the environment, require additional study to establish adequate testing criteria. <Creation of pressures lower than $10^{-10}$ torr permits investigation of surface effects such as cold welding, friction, sublimation, and outgassing.) In order to study these phenomena to define the level and duration of space simulation tests of $\mathrm{S} / \mathrm{C} /$ a moderate size space simulator capable of pressures in the range of $10^{-12}$ to $10^{-16}$ torr is being constructed at Goddard space Flight center.

The achievement of ultra-high vacuum in a test chamber requires minimization of the real leak rate and the incorporation of a pumping system to provide a high pumping speed at ultra-high vacuum for those gases desorbed from the test object in the chamber. The space simulator is to consist of a series of concentric chambers, providing a guard vacuum for the inner chamber which forms the working test volume. Thus, "real" gas inleakage into the test volume is minimized. High pumping speeds at ultra-high vacuum are to be provided by cryogenics. The walls of the inner chamber will be cooled to $15^{\circ} \mathrm{K}$ to $20^{\circ} \mathrm{K}$ by circulating gaseous helium through coils attached to the walls. For gases such as hydrogen, helium or neon, which are non-condensable at $20^{\circ} \mathrm{K}$, or whose sticking coefficient on a $20^{\circ} \mathrm{K}$ surface is quite low, a cryosorption array is provided. Cryosorption refers to the adsorption of a gas on a surface maintained at cryogenic temperatures. The advantages of cryosorption pumping have been 
recognized in the past, but two engineering difficulties have prevented its direct use in space simulation chambers. One was maintaining the surface of a bed of adsorbent at $20^{\circ} \mathrm{K}$, the other was simply that of retaining the adsorbent in the chamber so as not to contaminate the test space. Both problems appear to have been solved by the recent successful bonding of an adsorbent material to a metallic plate, the bonding being unaffected by temperature cycling from room temperature down to $20^{\circ} \mathrm{K}$. Data obtained from these panels indicate a high pumping speed for hydrogen at 10-8 torr accompanied by a large adsorptive capacity for hydrogen. Theoretical isotherms were used to predict the performance of these cryosorption panels at total pressures of $10^{-15}$ torr, with results indicating promise for success at these pressures 。

The advantages of cryosorption with $15^{\circ} \mathrm{K}$ to $20^{\circ} \mathrm{K}$ surfaces over a system utilizing liquid helium cooled walls at $4.2^{\circ} \mathrm{K}$ to condense hydrogen are described. Comparisons are made on the basis of both performance and cost. Results of the analysis illustrate the reasons for the choice of cryosorption over the more conventional liquid helium systems. It is believed that, at this time, the space simulator described herein is the only one designed to utilize cryosorption to maintain vacua in the $10^{-12}$ to $10^{-15}$ torr range.

Performance estimates are shown, indicating the ultimate pressures in the test volume of the integrated system, both for an empty chamber and for a spacecraft subsystem with various rates of outgassing. 


\section{CONTENTS}

Page

Summary . . . . . . . . . . . . . . . iii

I. INTRODUCTION .................. I

II. PRESENT SPACE SIMULATORS . . . . . . . . . 3

III. CRYOSORPTION . . . . . . . . . . . . . 4

IV. SYSTEM DESIGN AND OPERATION . . . . . . . . . ?

V. INSTRIMENTATION . . . . . . . . . . . 9

BIBLIOGRAPHY . : . . . . . . . . . . . . 11

LIST OF ILLUSTRATIONS . . . . . . . . . . 13 
CRYOSORPTION - A METHOD

FOR SIMULATING

THE SPACE VACUUM

ENVIRONMENT

by

J. E. A. John - W. F. Hardgrove

Goddard Space Flight Center

\section{INTRODUCTION}

The purpose of environmental testing in a satellite program is to establish the suitability for flight of a given flight unit. Satellites may be considered unique in that they are vitrually one of a kind. Usually a prototype, a flight unit, and a backup flight unit are the only complete assemblies that are made. (1) The variations between individual elements coupled with the unpredictable interactions and dependencies that prevail reduce formal mathematical reliability assessments to that of indicating trends in the relative strength of the system elements. The development of a high confidence level for the required dependability of today's spacecraft places a heavy demand on extensive testing and experimentation. The complexities of spacecraft such as the orbiting observatories, space probes and manned missions create the requirement for advanced testing techniques. Testing techniques and criteria become increasingly exacting in the region of ultra high vacuum, where the investigations may involve the cold welding of materials, variations in the coefficient of friction of sliding and rotating parts, changes in the optical properties of thermal control coatings, and other surface effects.

The present knowledge of the vacuum environment is based on scientific observations and theoretical concepts. Pressure decreases roughly by a factor of 10 for each 10 miles increase in altitude up to about 60 miles $(100 \mathrm{Km})$ : at 100 miles the pressure is approximately $10^{-6}$ torr (Figure 1)。 In other words all but one-one billionth of the earth's atmosphere lies below 100 miles. It changes by a factor of 10 in the next 100 miles. At 500 miles it is about $10^{-9}$ torr and at 1000 miles about $10^{-10}$ torr. The vacuum in interplanetary space is estimated to be between $10^{-12}$ and $10^{-14}$ torr. In intergalactic space a value of $10^{-16}$ torr is often assumed. (2) 
A major problem in creating the vacuum of the space environment in a terrestrial simulator is that of achieving an infinite sink for the molecules evolving from the experiment. The environmental space simulator presents a further complication in that the facility itself presents several sources of continuing gas loads that can be imposed on the experiment. Of these sources inbleed through leakage, outgassing of materials and chamber wall absorbed gases impose the largest gas loads. Simulation of the low density environment of space in a ground based test facility would therefore require that the walls of the chamber must have an infinite pumping capacity, i.e., capture all molecules colliding with it.(3)

Obviously because of feasibility and economical considerations duplication of the space environment cannot be accomplished in space simulators. However, the effects of the space vacuum as they are known today can be created and studied. Therefore, it is in this direction that testing and evaluation of spacecraft systems and components must be accomplished.

It is generally accepted that the effects from the vacuum environment that a spacecraft component or system experiences are a function of the level of vacuum. Depending upon the configuration a spacecraft takes, systems and components can be subjected to varying levels of vacuum. For example, one would not expect a component installed in an electronic box inside a spacecraft to operate at the same level of vacuum as that of a mechanical device operating on the surface. In such a case the electronic package might malfunction because of heat transfer effects while the mechanical device could fail due to cold welding.

The known effects and levels of vacuum at which they occur are shown in Figure 2. Where verification of thermal balance calculations or other such investigations are required, a vacuum of 10-5 torr is adequate to eliminate heat transfer by convection. Areas of test, evaluation, and study such as radiant heat transfer, corona, material evaporation, etc.. necessitate vacuum levels down to 10-8 torr. The first generation of space simulators currently in use are in the main capable of operating at vacua $10^{-7}$ - 10-10 torr. 
The great majority of space simulators in operation today utilize oil diffusion pumps with mechanical roughing pumps. The ultimate vacuum attainable with such a system is limited by the vapor pressure of the oil involved. Thus, such simulators are generally capable of achieving a vacuum of only $10^{-8}$ to $10^{-10}$ torr, the actual value dependent on the integrity of the vacuum vessel. Further, the utilization of oil diffusion pumps incurs the possibility of oil backstreaming from the pump into the test chamber, condensing on the test object and affecting the results of a test. Baffling of the pump tends to minimize this problem, but at the expense of pumping speed.

Cryogenic pumping offers several advantages over a more conventional pumping system (Figure 3). The chamber walls themselves can act as the pump, and thus there are no limitations due to port sizes. Further, volumetric pumping speed is independent of chamber pressure, at least until the ultimate pressure approaches the vapor pressure of the gas being cryopumped.

Disadvantages of cryogenics are the cost involved in maintaining surfaces at $20^{\circ} \mathrm{K}$ or perhaps $4.2^{\circ} \mathrm{K}$ and also the problems associated with pumping gases that have appreciable vapor pressures at the cryosurface temperature.] For example, the vapor pressure of hydrogen at $20^{\circ} \mathrm{K}$ is $760 \mathrm{~mm}$. $\mathrm{Hg}$; i even at $4.2^{\circ} \mathrm{K}$, its vapor pressure is $10^{-8}$ torr. Thus, in the presence of large volumes of hydrogen, cryogenic pumping alone would not be capable of operating much below this pressure.

For an initially empty chamber, the percentage of hydrogen gas is very small. Thus/space simulators using walls cooled with liquid helium to $4.2^{\circ} \mathrm{K}$, have been operated down to 10-15 torr (4). However, in the presence of a spacecraft or component which continually may introduce a hydrogen gas load into the chamber, the ultimate pressure of such a vacuum system may be several orders of magnitude higher.

What is needed, then, is a system providing the advantages of cryogenic pumping yet also possessing a reserve pumping capacity at ultra high vacuum for the non-condensable gases. 
To be economically sound it would further be desirable to be able to operate at as high a cryopanel temperature as possible. The cost of operating a system at $4.2^{\circ} \mathrm{K}$ for a protracted period is extremely great.

It is believed that the incorporation of a cryosorption array into a conventional cryopumped vacuum system solves these problems. Such a system will be shown to be economically feasible, and also capable of operating in the 10-15 torr region in the presence of an appreciable gas load from a test.

III. CRYOSORPTION

Cryosorption refers to the adsorption of a gas on a surface maintained at cryogenic temperatures. The potentialities of cryosorption have been recognized in the past, but two engineering difficulties have prevented its use. One is the problem of containment; the adsorbent material must be maintained in such a manner as to prevent particles of the adsorbent or adsorbent dust from passing into the test volume and affecting a test. Second, an adsorbent material, by its nature, has a low thermal conductivity; thus, a layer of adsorbent of appreciable thickness is difficult to maintain at a uniform temperature. The surface temperature of the adsorbent exposed to the gas to be pumped, may be several degrees greater than that at the bottom of the bed, where the cryogenic fluids are circulated. It will be shown that the performance of a cryosorbent is very greatly dependent on adsorbent temperature, so large temperature gradients through the bed cannot be tolerated. To solve these two problems, it is necessary to be able to bond a very thin layer of adsorbent to a metal plate.

The bond must be able to withstand temperature cycling from bakeout temperatures to cryogenic temperatures without failure. Zeolite has been successfully bonded to stainless steel surfaces with epoxy (5) for a short duration test. However, it was found that, over a long period, the epoxy would diffuse into the adsorbent, preventing hydrogen adsorption. Hemstreet et al.(6) have recently reported the successful direct bonding of molecular sieves to an aluminum plate, without the use of any adhesive not normally found in the sieve. The resultant bond was found to be very resistant to thermal shock. This bonding technique has proven successful with any molecular sieve material. 
In order to select the most beneficial sieve material, two parameters are of interest: first, the pumping speed for hydrogen at ultra high vacuum and, second, the adsorptive capacity of the sieve material for hydrogen over the pressure range of interest. Data obtained by stern(7) and Hemstreet(6) over the range $10-8$ to 10-10 torr indicate that molecular sieve 5A, filled with aluminum flake to improve its heat transfer characteristics, is the best material for use in a vacuum chamber.

It should be noted that the data mentioned have been obtained in the $10^{-8}$ to $10^{-10}$ torr range. However, it is desired to apply the cryosorption technique at vacuum levels down to 10-15 torr. Current instrumentation is not able to provide precise determinations of the parameters of interest at these pressures. Further, investigations up to the present have been interested in utilizing cryosorption only as a pumping device to handle large gasloads in the 10-8 to 10-10 torr range(8); thus there is a lack of data in the pressure range of interest for this work.

However, data obtained at higher pressure levels can be used to obtain an insight into the performance of a cryosorption panel at 10-15 torr.> Hemstreet (6) measured a hydrogen adsorption coefficient of 0.16 at $10^{-8}$ torr for a molecular sieve $5 \mathrm{~A}$ surface bonded to aluminum and maintained at $20^{\circ} \mathrm{K}$. This corresponds to an unbaffled pumping speed for hydrogen of 6600 liters / sec $\mathrm{ft}^{2}$ of adsorbent. This pumping speed was relatively insensitive to the volume of adsorbed hydrogen, at least until an appreciable fraction of the adsorbent surface was covered. Kindall(9) has demonstrated, from the results of experimental work, that volumetric adsorption rate is independent of pressure, so it would appear logical to assume that pumping speeds measured at 10-8 torr can be also obtained at 10-15 torr.

of fundamental significance in the operation of a cryosorption system is the adsorption isotherm of the adsorbent for the gas to be pumped, i.e., the relation between adsorption capacity and gas pressure for a fixed adsorbent temperature. The Dubinin-Radushkevitch equation (10) has met with success in predicting the adsorption of nitrogen on pyrex glass at $77^{\circ} \mathrm{K}(11)$, and that of hydrogen on charcoal at $20^{\circ} \mathrm{K}(12)$. According to this relationship: 


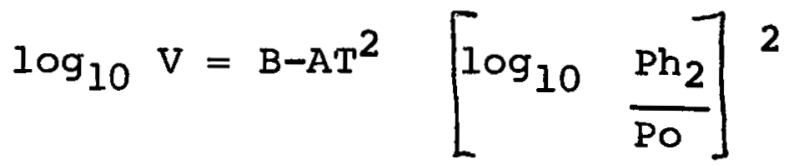

where $\mathrm{V}=$ Volume adsorbed at hydrogen pressure

$\mathrm{Ph}_{2}$ (cc at STP)

Po = Vapor pressure of liquid adsorbate at temperature of experiment

A, $B=$ experimental constants

Utilizing experimental data obtained at $10^{-6}$ to $10^{-9}$ torr (7) for the adsorption of hydrogen on molecular sieve 5A, the experimental constants were determined. The resultant plot of the $20^{\circ} \mathrm{K}$ isotherm is shown in Figure 4. It can be observed that, at a pressure of 10-15 torr, the adsorption capacity is .0009 standard cc/gram of adsorbent, or $6.8 \times 1011$ liters of hydrogen per gram at $10^{-15}$ torr. If the test chamber cryosorption panels have a combined surface area of five square feet, corresponding to 460 grams of adsorbent, the total capacity would amount to $3.2 \times 10^{14}$ liters of hydrogen at $10^{-15}$ torr. If there were to be a hydrogen gas load of 10-8 torr liters per second from the test object, the panel would not be saturated for 9000 hours, approximately one year.

This demonstrates that the cryosorption panel can be used for a long term test with no need for regeneration. The panel must be baffled in order to prevent gases other than hydrogen from reaching the adsorbent. Small volumes of condensable gases, such as nitrogen or water vapor (6), on the adsorbent surface, cause a marked decrease in the capacity and pumping speed of the molecular sieve (Figure 5).

It is of interest to compare, at this point, the capabilities for handling hydrogen of a cryosorption system operating at $15^{\circ}$ to $20^{\circ} \mathrm{K}$ with those of a cryopump system operating with liquid helium at $4.2^{\circ} \mathrm{K}$, as has been constructed at other laboratories. Whereas the quoted pumping speed for cryosorption of hydrogen on Molecular Sieve 5A corresponds to an adsorption coefficient of 0.16 , the sticking coefficient for hydrogen on a $4.2^{\circ} \mathrm{K}$ surface is only about .01(13). 
Hence, cryosorption at $20^{\circ} \mathrm{K}$ provides higher pumping speeds than cryopumping at $4.2^{\circ} \mathrm{K}$. Further the cryosorption system has obvious economic advantages.

\section{SYSTEM DESIGN AND OPERATION}

The proposed system consists of three concentric chambers, the outer three feet in diameter by three feet high and the inner containing a test volume of size $20 " \times 20 "$ (see Figure 6).

The space between the outer two chambers is to be evacuated by a conventional pumping system consisting of a mechanical pump, liquid nitrogen cold trap and diffusion pump. Seals across the outer wall are to consist of double elastomer O-rings. The space between the O-rings is evacuated to provide a guard vacuum. The outer chamber will be baked out to minimize outgassing, and thus allow a lower pressure in this outer volume. Further, provisions have been made for cooling the o-rings to minimize gas permeation; considerable evidence(14) indicates that this technique is successful in improving the ultimate vacuum.

The intermediate chamber walls are to be cooled with liquid nitrogen to reduce the heat load on the walls of the inner chamber which are cooled to $15^{\circ} \mathrm{K}$ to $20^{\circ} \mathrm{K}$ by gaseous helium. The vacuum obtainable in the intermediate space should be at least an order of magnitude better than that existent in the outer space, since it is isolated from the possibility of in-leakage from atmospheric pressure. A separate pumping system, again consisting of a diffusion pump, liquid nitrogen cold trap, and mechanical pump, is to be used for initial evacuation of the intermediate space and test volume (Figure 7). The pressure, after pumpdown, should be approximately $10^{-10}$ to $10^{-11}$ torr in the test volume and surrounding guard vacuum.

After pumpdown, the valve connecting the test volume to the surrounding guard vacuum is closed, isolating the test volume from the mechanical and diffusion pumps. Gaseous helium is circulated in the walls of the test volume, cooling it to $15^{\circ} \mathrm{K}$ to $20^{\circ} \mathrm{K}$. Thus, oxygen, nitrogen and all other condensable molecules are cryogenically pumped, leaving only the noncondensables in the test chamber. Following this, gaseous helium at or below $20^{\circ} \mathrm{K}$ is circulated in the chevron baffles and cryosorption panel for pumping of 
residual hydrogen and helium. The baffles prevent molecules other than hydrogen or helium from reaching the cryosorbent panel. Thus, a system is provided that is capable of attaining ultrahigh vacuum and, further, has the capacity, at low pressures, for handling large gas loads (both of condensable and noncondensable gases) which would be outgassed from the spacecraft equipment under test.

One of the fundamental considerations involved in the design of a cryogenic pumping system is the heat loads on the cryogenic shrouds which determine either the amount of cryogenic fluids required or, in this case, the size of refrigerator required to supply gaseous helium at $15^{\circ} \mathrm{K}$ to $20^{\circ} \mathrm{K}$. Before cryogenic fluids are introduced, the system will have been pumped to a pressure level where the only heat transfer is due to radiation. The heat transfer, via radiation between a surface and another enclosing it, is given by:

$$
q=\frac{\left(.1714 \times 10^{-8}\right)\left(\mathrm{T}_{1}^{4}-\mathrm{T}_{2}^{4}\right) \mathrm{A}_{1}}{\frac{1-\varepsilon_{1}}{\varepsilon_{1}}+\frac{\left(1-\varepsilon_{2}\right) \mathrm{A}_{1}}{\varepsilon_{2} \mathrm{~A}_{2}}+1}
$$

where:

$$
\begin{aligned}
\mathrm{q} & =\text { heat transfer rate }(\mathrm{Btu} / \mathrm{hr}) \\
\varepsilon_{1}, \varepsilon_{2} & =\begin{array}{l}
\text { emissivities of surfaces, assumed } \\
\text { equal to absorptivities }
\end{array} \\
\mathrm{A}_{1}= & \text { enclosed area }\left(\mathrm{ft}^{2}\right) \\
\mathrm{A}_{2}= & \text { enclosing area }\left(\mathrm{ft}^{2}\right) .
\end{aligned}
$$

The values of $\mathcal{E}$ for condensate-coated surfaces can be assumed as approximately .10, since the thickness of the coating will be quite small for the pressures involved(15). Under steady-state conditions, the heat exchange between the $77^{\circ} \mathrm{K}$ surface, of surface area $29.4 \mathrm{ft}^{2}$, and the $20^{\circ} \mathrm{K}$ surface, of area $18.8 \mathrm{ft}^{2}$, will then amount to:

$$
\mathrm{q}=.76 \mathrm{Btu} / \mathrm{hr} \text { or } .22 \text { watts. }
$$

If there is a test object in the chamber maintained at room temperature, the gaseous helium refrigeration 
requirements greatly increase. If it is assumed that the test object is black ( $\varepsilon=1)$, in the form of a one-foot diameter sphere (surface area $=3.14 \mathrm{ft}^{2}$ ) and maintained at $273^{\circ} \mathrm{K}$, the heat load increases to:

$$
q=127 \mathrm{Btu} / \mathrm{hr} \text { or } 37.3 \text { watts. }
$$

This estimate of heat load is optimistic in that no account has been taken of the heat transfer by conduction through support rods, cryogenic piping, etc., or of the refrigeration requirements during initial cooldown. However, the heat load due to radiation from the surrounding shroud and from the test object certainly represents the largest part of the refrigeration required. In any case, the load is within the capacity of a 250-watt helium cryostat.

V. INSTRUMENTATION

In order to specify the environment to which a test object has been subjected, it is necessary to be able to measure the pressure or molecular flux at several points in the test chamber and also, to be able to determine the predominant molecular species, and their partial pressures.

Figure 8 shows the approximate pressure ranges of several different types of gauges. PThose of interest in this application, where the ultimate pressure will be of the order of 10-15 torr. Jinclude the cold cathode (Redhead) gauge, hot cathode gauge, and the mass spectrometers. It is significant that Alpert(16) asserts that the lowest known direct measurement of total pressure was $4 \times 10^{-13}$ torr, made by Lafferty (17) using a hot cathode, magnetron gauge. However, with any gauge operating at these pressure levels, especially the hot cathode gauges, there is the question of the contamination introduced into the chamber by surface effects (out-gassing, adsorption, etc.) taking place on the gauge itself. Obviously, it is a requirement of any measuring instrument not to change the environment in which it is inserted. It seems, at this time, that methods of achieving ultrahigh vacua have surpassed the means for measuring vacua.

Instrumentation for the chamber will have to be provided for measuring the principal constituents of the residual gas 
in the chamber at any time and their percentages of the total gas present. Alpert(16) indicates that a promising instrument at the present time is a high sensitivity, mass spectrometer developed by Davis(18) and capable of measuring partial pressures as low at $10^{-16}$ torr. Again, the accuracy of the instrument depends on a knowledge of the surface effects introduced by the instrument itself. Initial measurements will be made with a cold cathode, Redhead gauge and electrometer, capable of indicating pressures down to 10-13 torr. It is envisioned that, when the research chamber becomes available, improvements will have been made in gauging that will extend the measurable range down below the present level. It is anticipated that research will have to be done in order to amend mass spectrometers currently available to allow measurements of partial pressures of hydrogen, helium and other gases present in the chamber at $10^{-15}$ torr. 


\section{BIBLIOGRAPHY}

(1) Boeckel, John H., "The Purposes of Environmental Testing for Scientific Satellites", NASA Technical Note D-1900, July 1963

(2) New, J. C., "Scientific Satellites and the space Environment", NASA Technical Note D-1340, June 1962

(3) Male, D. W. and Pinson, J. D. Capt., "Molecular Flux in Space Environmental Simulating Facilities" Proceedings Institute of Environmental Sciences (1963)

(4) "Interplanetary Vacuum", Vacuum Technology, June 1964

(5) Narcisi, R. S., et al., "Zeolite Adsorption Pump for Rocket - Borne Mass spectrometer", Transactions AVS (1962)

(6) Hemstreet, R. A., et al., "The cryosorption Pumping of Hydrogen at $20^{\circ} \mathrm{K} "$, Linde Div.., Union Carbide Corp.. Tonawanda, N. Y. AEDC-TDR-64-100, May 1964

(7) Stern, S.A., et al., "The cryosorption Pumping of Hydrogen and Helium at $20^{\circ} \mathrm{K} "$, Linde Div., Union Carbide Corp., Tonawanda, N. Y., AEDC-TDR-62-200, October 1962

(8) Lennert, A. E., "Experimental studies of Vacuum Cryosorption Pumping", ARO Inc., AEDC - TDR-62-45, March 1962

(9) Kindall, S. M., "Treatment of Vacuum Cryosorption", Transactions AVS (1963)

(10) Dubinin, M., and Radushkevitch, L., Proceedings of Acad. Sci. USSR, 55 (1947)

(11) Hobson, J.. "Physical Adsorption of Nitrogen on Pyrex at Very Low Pressures," J . Chem. Phys., 34, 1850 (1961)

(12) Beyer, G., "Cryosorption," paper contributed to Final Report of Goddard Summer Workshop Program, NASA Report $\mathrm{X}-320-63-264$ (1963)

(13) Bachler, W., Klipping, G., and Mascher, W., "Cryogenic Pump Systems Down to $2.5^{\circ} \mathrm{K}$," Transactions AVS (1962) 
(14) Farkass, I., Gould, P., and Horn G., "1 $\times 10^{-11}$ Torr in Large Metal Chambers," Transactions AVS (1962)

(15) Moore, B., "Effect of Gas Condensate on Cryopumping," Transactions of Ninth Vacuum Symposium, American Vacuum Society (1962)

(16) Alpert, D., "Ultra-High Vacuum: A Survey," Physics Today, August (1963)

(17) Lafferty, J ., "The Hot-Cathode Magnetron Ionization Gauge with an Electron Multiplier Detector, " Transactions AVS (1962)

(18) Davis, W., "Sputter-Ion Pumping and Partial Pressure Measurements Below 10-11 Torr," Transactions AVS (1962) 


\section{ILLUSTRATIONS}

Figure No.

Structure of the Earth's Atmosphere . . . . . . . I

Effect vs. Pressure Simulation . - . . . . . . . 2

Pumping Methods for Space Chambers . . . . . . . 3

Equilibrium Adsorption of Hydrogen on Molecular

Sieve $5 \mathrm{~A}$ at $20^{\circ} \mathrm{K}$. . . . . . . . . . . . 4

Effect of Nitrogen Frozen on Surface on

Pumping Speed . . . . . . . . . . . . . . 5

Conceptual Design for Cryosorption Modification

to $3^{\prime} \times 3^{\prime}$ Vacuum Chamber . . . . . . . . . 6

Ultra High Vacuum Space Simulator . . . . . . . 7

Range of Application for Various Vacuum Gauges . - 8 


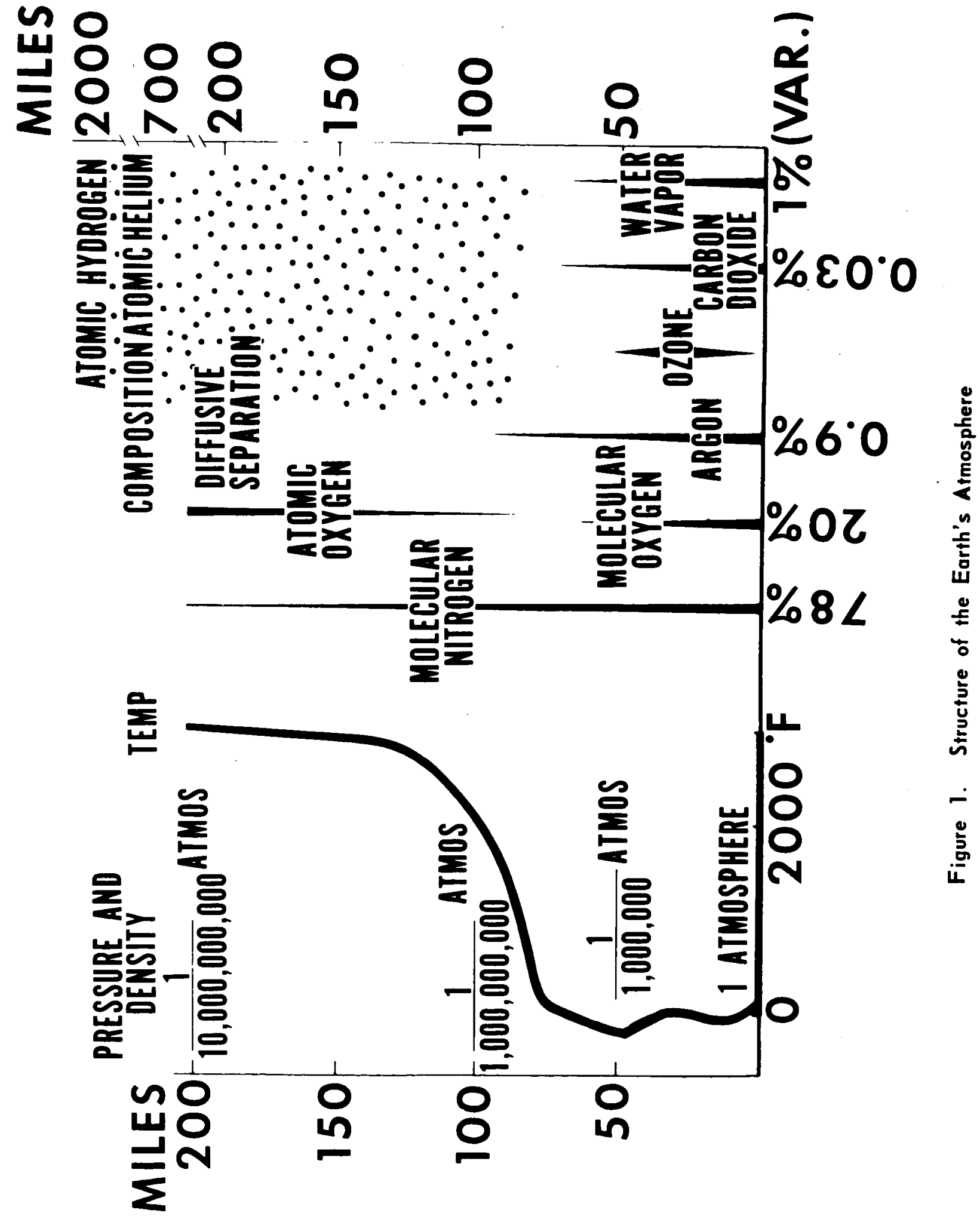




\begin{tabular}{|c|c|c|}
\hline Effect & vs & $\begin{array}{l}\text { Pressure } \\
\text { Simulation } \\
\end{array}$ \\
\hline - Corona & & ATM to $10^{-4} \mathrm{mmHg}$ \\
\hline $\begin{array}{l}\text { Heat Transfer, Radiation } \\
\text { Predominates }\end{array}$ & & $10^{-4}$ to $10^{-5}$ \\
\hline $\begin{array}{l}\text { Evaporation, Sublimation } \\
\text { Decomposition }\end{array}$ & & $\begin{array}{c}<10^{-5} \mathrm{mmHg} \text { MFP }> \\
\text { Mean Distance to } \\
\text { Condensing Walls }\end{array}$ \\
\hline $\begin{array}{l}\text { Liberation of Absorbed } \\
\text { Gas }\end{array}$ & & $\begin{array}{c}<10^{-5} \mathrm{mmHg} \\
\text { (High Pumping Speeds) }\end{array}$ \\
\hline $\begin{array}{l}\text { Liberation of Adsorbed } \& \\
\text { Chemisorbed Gas }\end{array}$ & & $10^{-7}$ to $10^{-16} \mathrm{mmHg}$ \\
\hline
\end{tabular}

Figure 2 


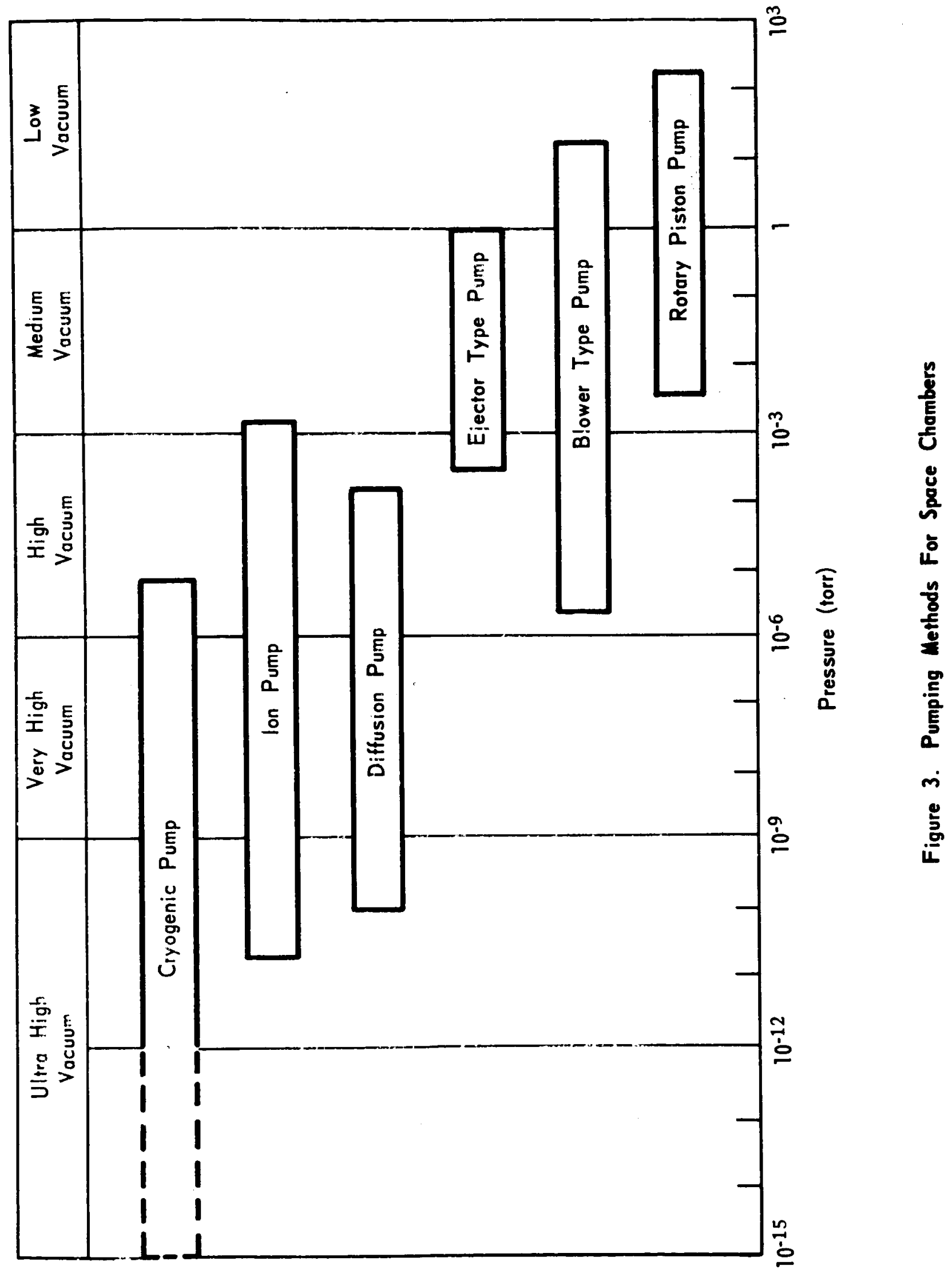




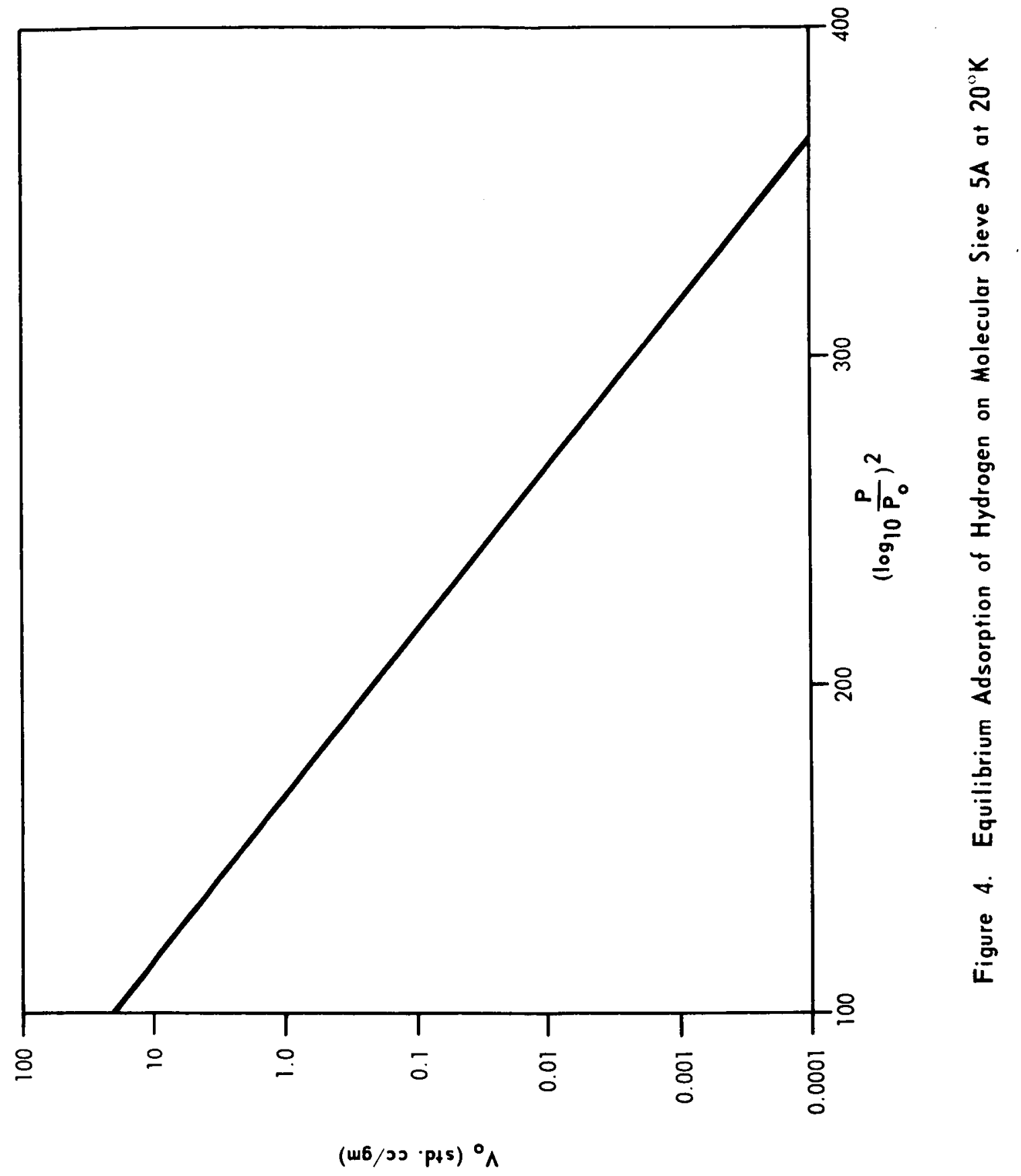




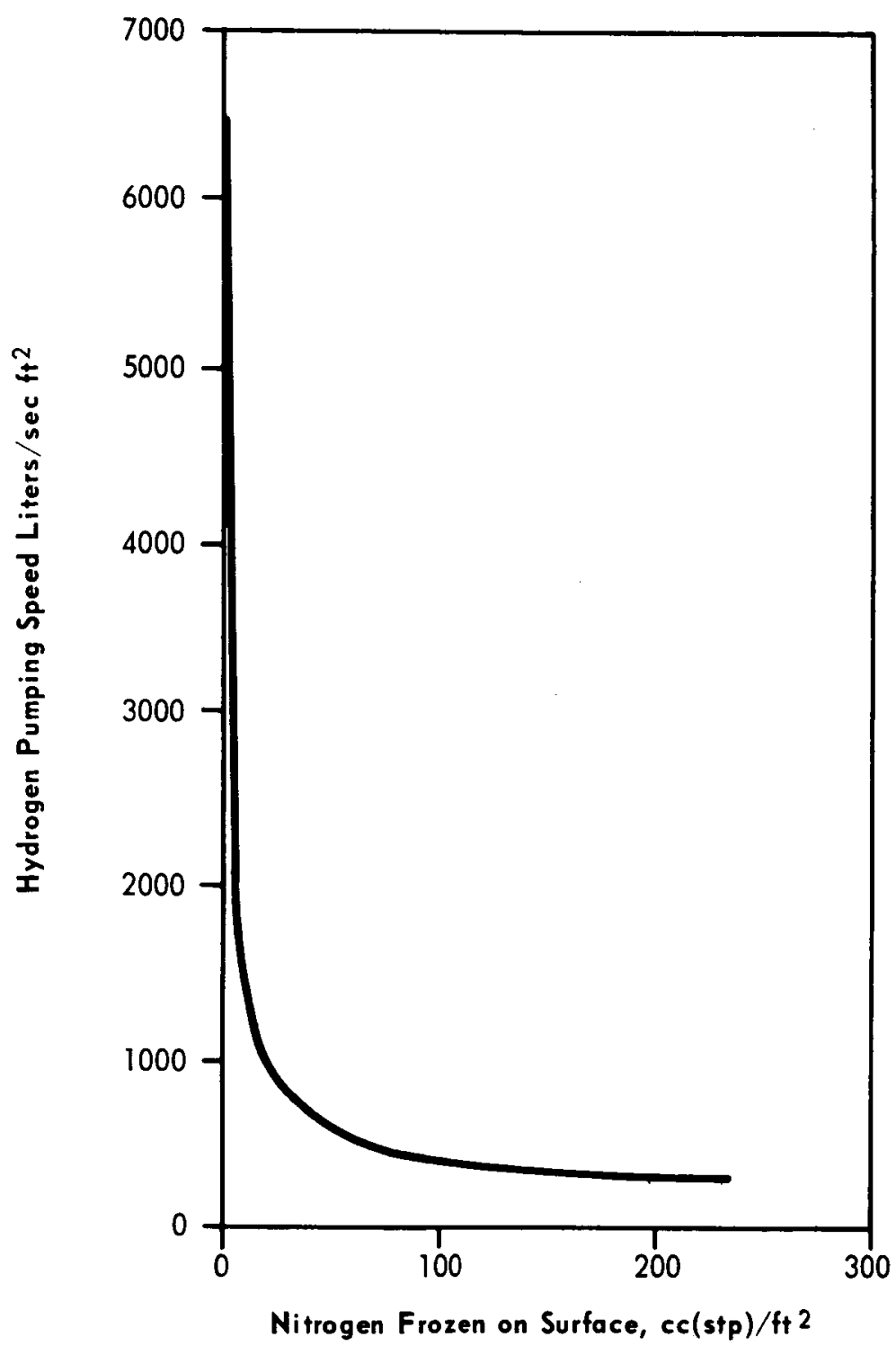

Figure 5. Effect of Nitrogen Frozen on Surface on Pumping Speed 


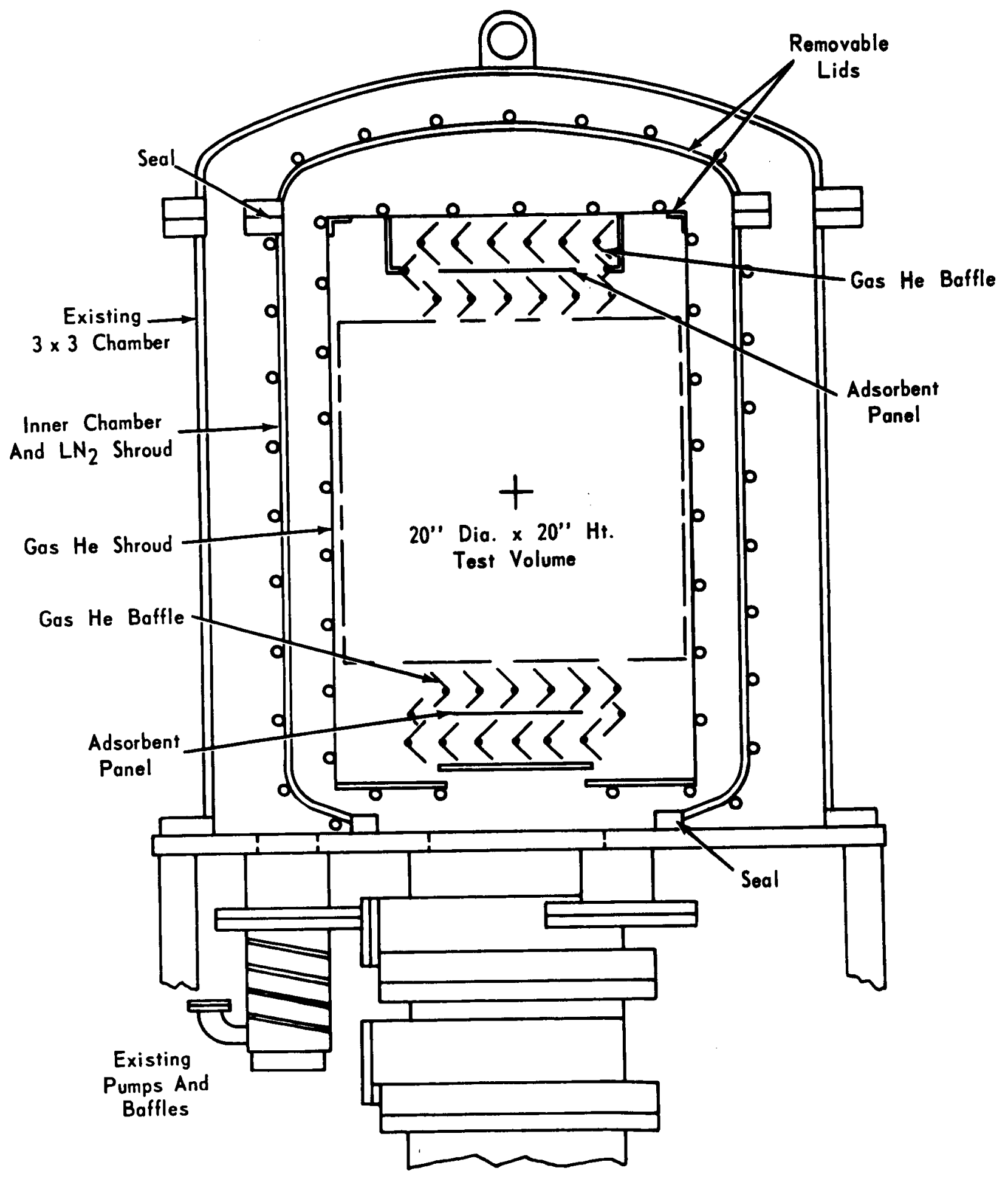

Figure 6. Conceptual Design For Cryosorption Modification To $3^{\prime} \times 3^{\prime}$ Vocuum Chamber 


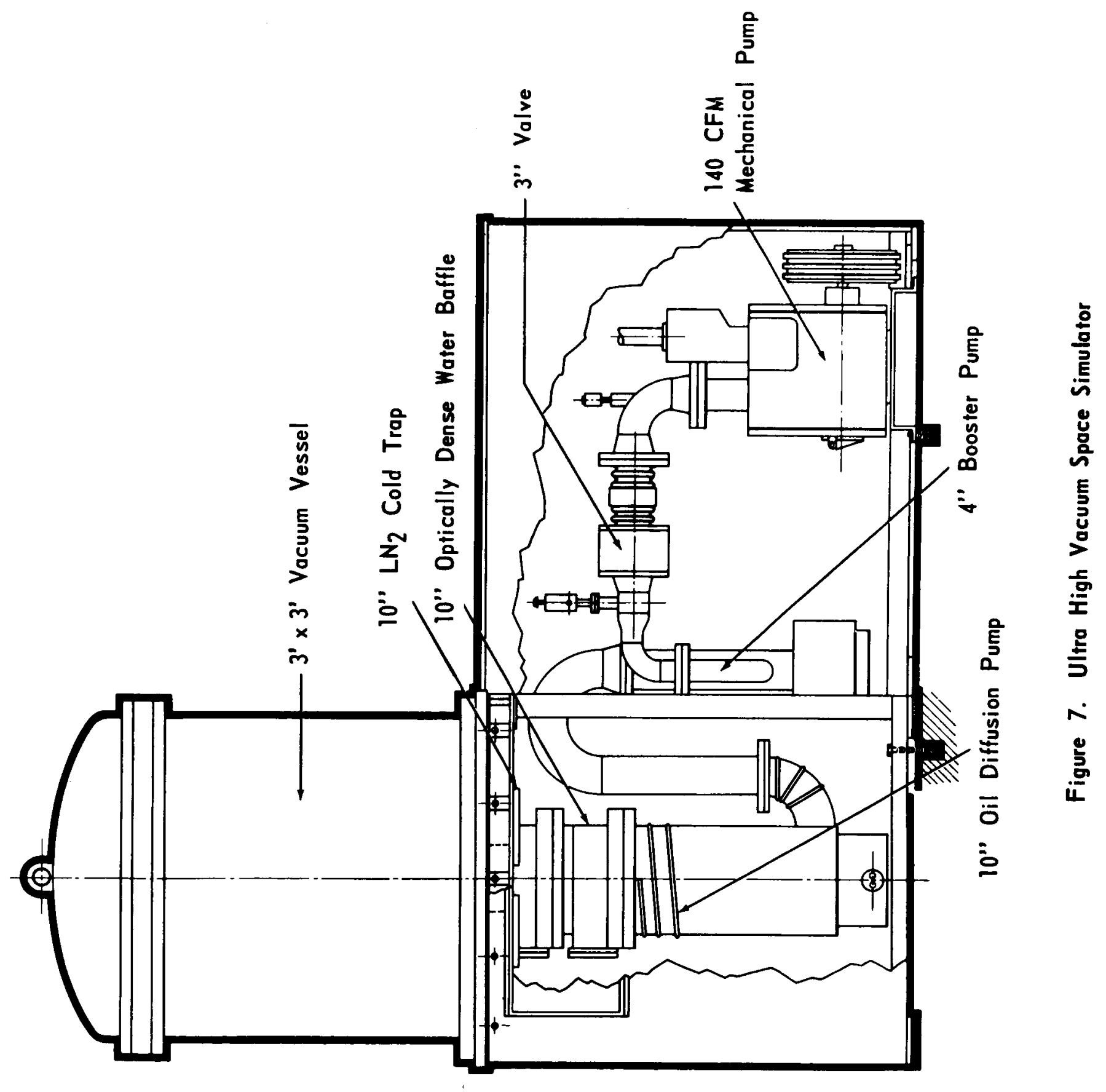




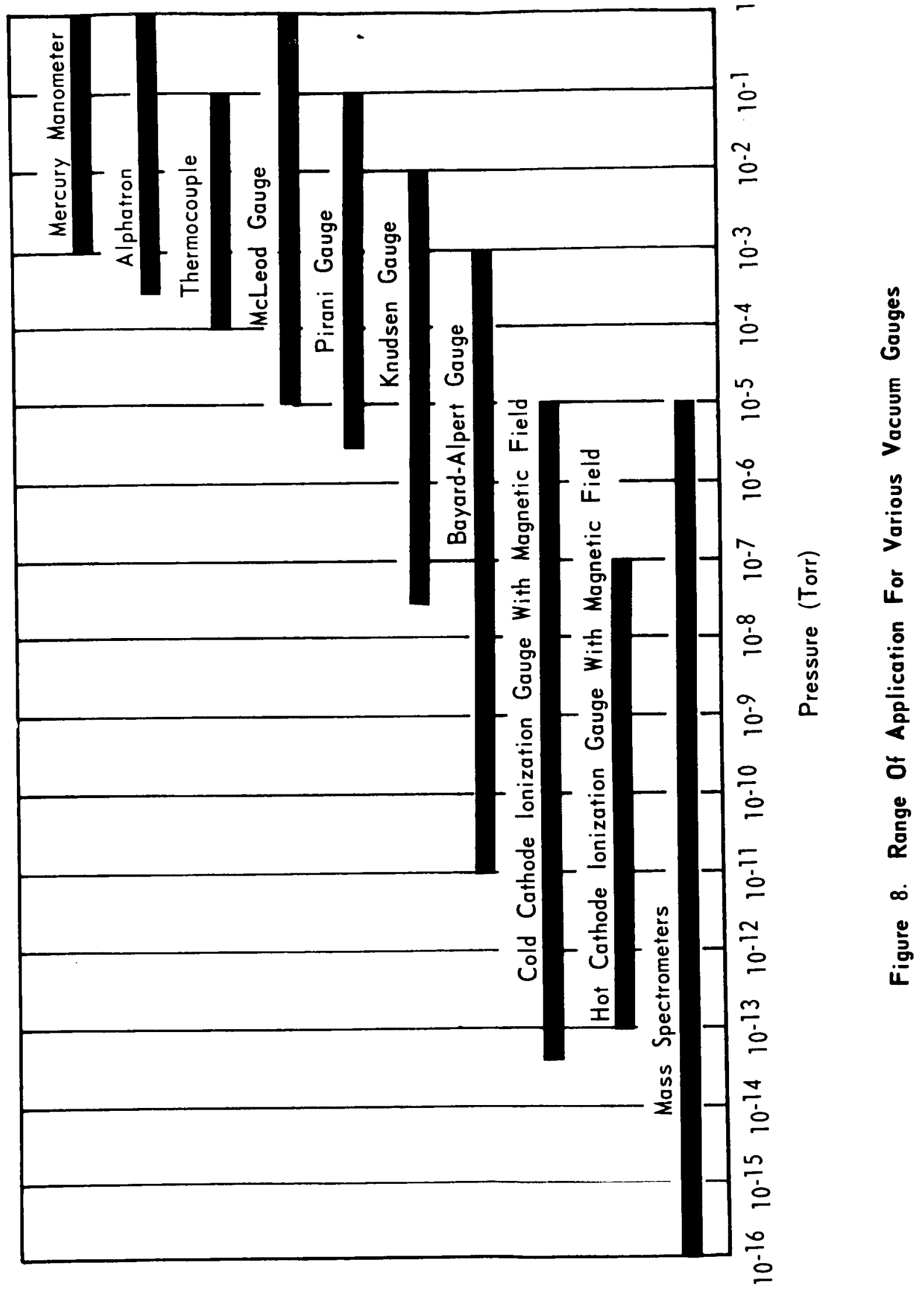


Chief, Technical Services

Chief, Test \& Evaluation Division

Associate Chief, Test \& Evaluation Division

Assistant Chief, Operations

Head, Thermodynamics Branch

Head, Thermal-Vacuum Test Section (2)

2

3

4

5

Head, Thermal-Vacuum Facilities Section (2)

$6-7$

$8-9$

Head, Vacuum Research and Technology Section (2)

$10-11$

D.C. Kennard, Jr., Tech. Asst. for Advanced Research \& Technology (2)

$12-13$

W. F. Hardgrove, Vacuum Research \& Technology Section (5)

J.E.A. John, Vacuum Research \& Technology Section (5)

R. J. LeDoux, Test and Evaluation Division 